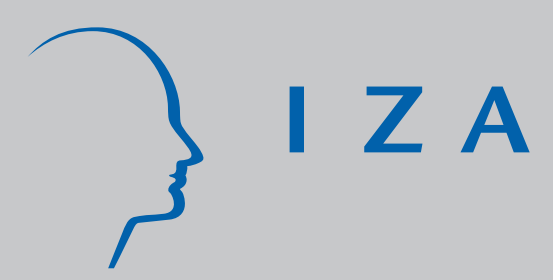

IZA DP No. 5861

Socio-Spatial Mobility in British Society

William A.V. Clark

Maarten van Ham

Rory Coulter

July 2011

Forschungsinstitut

zur Zukunft der Arbeit

Institute for the Study

of Labor 


\title{
Socio-Spatial Mobility in British Society
}

\author{
William A.V. Clark \\ University of California at Los Angeles \\ Maarten van Ham \\ Delft University of Technology \\ and IZA \\ Rory Coulter \\ University of St Andrews
}

\section{Discussion Paper No. 5861 \\ July 2011}

IZA

P.O. Box 7240

53072 Bonn

Germany

Phone: +49-228-3894-0

Fax: +49-228-3894-180

E-mail: iza@iza.org

Any opinions expressed here are those of the author(s) and not those of IZA. Research published in this series may include views on policy, but the institute itself takes no institutional policy positions.

The Institute for the Study of Labor (IZA) in Bonn is a local and virtual international research center and a place of communication between science, politics and business. IZA is an independent nonprofit organization supported by Deutsche Post Foundation. The center is associated with the University of Bonn and offers a stimulating research environment through its international network, workshops and conferences, data service, project support, research visits and doctoral program. IZA engages in (i) original and internationally competitive research in all fields of labor economics, (ii) development of policy concepts, and (iii) dissemination of research results and concepts to the interested public.

IZA Discussion Papers often represent preliminary work and are circulated to encourage discussion. Citation of such a paper should account for its provisional character. A revised version may be available directly from the author. 


\section{ABSTRACT}

\section{Socio-Spatial Mobility in British Society}

The research reported in this paper examines the nature and extent of socio-spatial mobility in the United Kingdom. In contrast with previous studies, we do not only investigate who moves out of deprived neighbourhoods, but our models cover the entire spectrum of neighbourhoods and provide a more complete interpretation of the process of mobility across socio-spatial structures. We use the Index of Multiple Deprivation (IMD) to classify neighbourhoods defined as small areas containing approximately 1500 people. We use the data from all available waves of the British Household Panel Survey (BHPS) to trace moves between these neighbourhoods, classified into deprivation deciles. We define upward sociospatial mobility as moving to neighbourhoods with lower levels of deprivation. The focus on residential choices and the outcomes - residential sorting - allows us to measure the fluidity of the British social structure. We show that restricted ability to compete for the better neighbourhoods combines with residence in neighbourhoods with relatively high degrees of deprivation to limit opportunities for social mobility. The analysis shows that education and income play critical roles in the ability of individuals to make neighbourhood and decile gains when they move. There are also powerful roles of being unemployed and being (and becoming) a social renter. Both these latter effects combine to seriously restrict the possibilities for socio-spatial movement for certain groups. The results suggest serious structural barriers to socio-spatial mobility in British society, barriers which are directly related to the organisation of the housing market.

JEL Classification: J61, R23

Keywords: residential sorting, residential mobility, socio-economic status, deprivation, neighbourhoods

Corresponding author:

William A.V. Clark

Department of Geography

University of California at Los Angeles

Los Angeles, CA 90095-1524

USA

E-mail:wclark@geog.ucla.edu 


\section{Introduction}

A socially mobile and fair society is a key aim of the UK government, with improving the social mobility of the population a principal goal of the current Coalition Government's social policy. According to the report Opening Doors, Breaking Barriers: A Strategy for Social Mobility "In Britain today, life chances are narrowed for too many by the circumstances of their birth: the home they're born into, the neighbourhood they grow up in or the jobs their parents do. Patterns of inequality are imprinted from one generation to the next" (Nick Clegg in Cabinet Office, 2011). The neighbourhoods we live in to a large extent reflect our socioeconomic position in society, as our purchasing power determines the quality of the neighbourhood we can access (Cheshire, 2011). As such, the opportunity to move and especially the opportunity to leave less advantaged neighbourhoods for more desirable locations, is central for achieving social mobility. Moving to a more advantaged neighbourhood is associated with greater opportunities, and, at the same time, an escape from the problems that are concentratedin less advantaged places.

While there is a large literature examining social mobility in terms of income, social class and employment status (Goldthorpe and Llewellyn, 1987), less is known about the mobility of people between different types of neighbourhoods (van Ham and Clark, 2009). Do households at the bottom of the social scale have the opportunity to move out of poorer neighbourhoods, or is society so structured that inertia debilitates their chances for social change? Even less is known about those who are not socially mobile at all, those who move but only to a similar type of neighbourhood, or even move down the neighbourhood hierarchy. However, it is just this issue of neighbourhood stability which may be most critical in understanding the amount of social change which occurs in a society.

Our analysis has dual foci - to improve our understanding of residential mobility in the context of local places and their characteristics, and to measure the odds of people changing their position within the whole socio-spatial system. There have been experimental attempts to measure the outcomes of residential mobility in the United States (Rosenbaum, 1995;Johnson et al., 2002; Clark, 2008), but the research on whether (and which) households gain from these moves has been inconclusive. At least one argument explaining the relative paucity of research information is that the surveys used have run over a relatively short time interval. The long term (nearly two decade) run of the British Household Panel Survey (BHPS) provides an important research data base to realistically evaluate the role of residential mobility in creating social change in the UK. Using a longitudinal resource such as the BHPS also enables us to analyse socio-spatial stability, as we can identify individuals who are immobile over long periods of time.

The overall aim of this project will be to examine whether residential mobility results in upward social mobility, especially for poorer households, and how such effects compare with middle and higher income households. The central questions are - how much social mobility takes place and can "poor households" affect upward social mobility with residential change? Or is it only the affluent who can move and move up, so that poor households are marginalized and left to "pick up the pieces". Their mobility as well as their location may therefore be largely residualised within the larger urban mosaic.

\section{The Conceptual structure - life course behaviour}

Households and individuals progress through family, occupational, housing and neighbourhood careers (Clark and Dieleman, 1996; Mulder, 1993). At varying points in the life course, changes occur in any one of these careers and those changes impact the trajectories of the other careers. The changes in any one of the careers can, and in the case of 
neighbourhood careers must, lead to residential moves (Mulder and Hooimeijer, 1999). Events such as getting a divorce andstarting or losing a job are known to have strong effects on the propensity for individuals to relocate (eg. Clark and Davies Withers, 1999; Mulder and Wagner, 2010). These life course transitionsmay also be played out in socio-spatial residential change, as individuals move from neighbourhoods of one status type to another.

\section{Life course behaviour and social progress}

We move to improve - the long history of mobility and migration has been infused by the notion that over the life course we make a series of moves to both bring our housing needs and employment opportunities into equilibrium, and to attain higher levels of satisfaction in our life course objectives (see Clark and Dieleman, 1996; Martin and Lichter, 1983). Indeed, government has now recognized that mobility leading to social advantage is a key mechanism for creating overall social gain. In the British context, the aforementionedStrategy for Social Mobility and the Higher Ambitions report prepared by the Department for Business, Innovation and Skills (2009) both recognize that greater social fluidity benefitssociety as a whole. Thus, social mobility is a key government issue and one which has implications for the rising inequality that is often identified as a problem in British society (eg. Dorling, 2010).

In addition toemphasising social mobility, the UK government has also responded to inequality with Place Based Initiatives. Based on the belief that where you live shapes your access to opportunity (see van Ham and Manley, 2010), there has been a longstanding concern with creating "communities of opportunity" - places with good schools, access to jobs, quality housing choices, safe streets, services and strong social networks. These excellent ideas about the effects of places of opportunity must be tempered with greater understanding about residential mobility and neighbourhood change. Places are created by the people in them and if there is greater, or alternatively smaller turnover, there are corresponding impacts on the people who live in these places. By focusing on places as well as people, these programs are concerned to integrate what have often been disparate approaches to social inequality and deprivation. Thus, the concern is now to understand how residential change is linked to social change and infrastructure outcomes. For instance, the increase in vacant houses caused by families leaving a neighbourhood can have an impact beyond the impact of a vacancy. Vacancies signal change and can be the beginning of the local disruption of social services, eventually leading to neighbourhood decline.

Societies often strive to limit the uneven distribution of household income for both equity and efficiency reasons. However, individuals and their families are highly correlated in socio-economic and educational terms. Where housing is allocated primarily through the market, families group spatially and generate distributional inequality (Worner, 2006; Cheshire, 2011). To what extent does this spatial organization of income inequality affect the opportunities of individuals and families to use residential mobility to enhance social mobility? Are some individuals less able than others to use mobility as a strategy for social gain?

To further complicate any investigation of mobility and place effects, patterns of socio-economic segregation are not static; they change although slowly as an aggregate result of individual adjustment decisions. Thus the central question of our study is truly appropriate in trying to disentangle mobility effects from place effects. To reiterate, our study asks which individuals and households adjust their housing and neighbourhood circumstances by moving. Answering this question on geographic adjustments is important for understanding whether the level of geographic segregation and potentially the uneven distribution of income maintains, increases or decreases as a result of the moves (Schill and Wachter, 1995).

As UK society continues to evolve, with an aging white population and growing immigrant populations, knowledge of how the spatial changes in these populations will play out in large and small cities in the United Kingdom will provide essential data and guidance for policy options. Opportunities for mobility are one of the most important dimensions 
related to escaping deprived neighbourhoods and for changing the distribution of equity. How well is the mobility process working for new immigrants especially, but for the native born poor as well? Mobility is the engine of change in the city and a better understanding of who gains and who becomes more marginalized through (im)mobility will enrich both our understanding, while suggesting possible policy responses. Thus, our study asks which individuals and households can adjust their housing and neighbourhood circumstances by moving and whether such geographic adjustments increase or decrease their economic and social mobility.

\section{Previous Research}

Economics and ethnicity play critical roles in how our metropolitan areas are arranged spatially. Over time, differences in economics and differences in ethnicity have created a residential mosaic that is stratified by both class and race (Friedman, 2011; South et al, 2005). It is across this mosaic that the choices of households are made, in turn reinforcing or changing the mosaic as the choices are executed. Thus the creation of neighbourhoods is not a random process, butis embedded in the preferences people reveal in their wish to live near similar households, in terms of income, composition (presence of children for example) and ethnicity.

That small differences in residential preferences play a powerful role in creating different areas within the city was demonstrated by Schelling (1971), who established that small differences in preferences can create and maintain separation in the residential fabric. The aggregate outcome of preferences is sorting, resulting in the grouping (segregation) of similar individuals into spatially defined areas (neighbourhoods) from which we observe common outcomes. If the residential sorting process leads to a widening of differences between neighbourhoods, some places will experience a more rapid descent socioeconomically than others. This descent process may in turn generate characteristics which may initiate threshold effects on the social behaviour of residents (Meen, 2006; Meen et al., 2012). In this sense, neighbourhoods can have the potential to generateeffects (both positive and negative) which result directly from residential sorting, as extensive reviews of the literature have shown (Dietz, 2002; Durlauf, 2004; Friedrichs et al., 2003).

There is now a vast international literature on residential mobility,although until very recently relatively little attention was directed towards the neighbourhoods that households enter, reside within andsubsequently exit (Clark and Rivers, 2012; van Ham and Feijten, 2008; Feijten and van Ham, 2009). This is now changing, with new studies of neighbourhood effects devoting increasing attention to processes of neighbourhood sorting (van Ham and Clark, 2009; Hedman et al., 2011). Much of this newer literature does not however focus specifically on the role of mobility, as the emphasis still tends to be on where people live and not where they move to. Even past research on why families move, and when, and with what consequence, is under contestation. The family itself is now a highly contested concept as dual-earning is common (LeClere and McLaughlin, 1997), the life course is considerably more complicated and varied (Clark and Dieleman, 1996;Flatau et al 2004), and possible reasons for moving are now highly differentiated (Clark and Dieleman, 1996). Both aging and affluence have increased the proportion of discretionary moves, thereby increasing the importance of life style and consumption based influences for mobility. The growing proportion of in-migrants from ethnic minority groups alters locational preferences as well.Enlarged commuting fields extend the range of residential adjustment options (Eliasson et al., 2003).Many of these factors impinge on choice of location, the duration of residence and the stage in our lives when we decide to move.

Despite the extensive documentation of sorting processes and on the residential fabric

more generally, there is much less research on the process of movement between 
neighbourhoods. Those studies which have focused on mobility have tended to examine the ability of people to move out of deprived neighbourhoods(South and Crowder, 1997, 2005; Quillian, 1999, 2003) or churning and mobility processes across deprived neighbourhoods (Robson et al., 2008). Those studies which have considered movement across a matrix of neighbourhoods have tended to focus more on movement across different ethnic contexts than across socio economic contexts (Bolt et al., 2008; Clark and Rivers, 2012). There have been comparatively few attempts to empirically examine the movements between a full range of neighbourhoods defined in socio economic terms. Recently, a New Zealand study of movement across a set of neighbourhoods found that the degree of upward mobility achieved is negatively affected by the level of deprivation at the neighbourhood of origin. Even after controlling for the attributes of movers, the more deprived the neighbourhood of origin, the lower the degree of upward mobility movers experience (Clark and Morrison, 2011). This finding suggests a high degree of inertia in socio-spatial mobility.

There is growing evidence that economics is becoming a more and more powerful factor in explaining thesocio-spatial outcomes of mobility. For example, the fact that Toronto's neighbourhoods have become considerably more polarised by income over the last few decades reflects the increasing attention assumed neighbourhood effects have received by those with the ability to choose (Hulchanski, 2007). As Hulchanski suggests, the greater the resources available to discriminate among possible places to live, the greater the likelihood that neighbourhoods will polarize. The recognition of polarization across neighbourhoods underlines the way in which selective migration processes can erode any gains made by public investment in place (Bailey and Livingston, 2008).

This recognition of polarization and growing poverty concentrations suggested to policymakers that enabling low income families to move from high to low poverty neighbourhoods could reduce the levels of income and racial segregation in US metropolitan areas (Rosenbaum and Popkin, 1991; Rosenbaum, 1995). The Moving to Opportunity (MTO) program in the US allowed poor, inner city households to use housing vouchers to gain access to neighbourhoods which could enhance their employment and educational opportunities and diminish their exposure to crime, violence and drugs. Some commentators suggested that these voucher programs would both benefit individual families and have the potential to deconcentrate poverty (Goering, 2005). However, the MTO research is far from clear on whether movement "policies" have produced the gains suggested by the proponents of voucher programs. While some suggest there are gains (Johnson et al., 2002; Goering, 2005), others question the nature and level of the outcomes (Clark, 2008; Varady and Walker, 2005; Sampson 2008).

The fact that assisted mobility to a better neighbourhood does not automatically lead to improved individual outcomes not only questions the neighbourhood effects hypothesis (van Ham and Manley, 2010), but by extension it also raises the question of whether those who move without assistance also make gains when they move. It is in the context of the full range of choices and constraints across the residential mosaic that we undertake this study of socio-spatial mobility.

\section{Data and Methods}

\section{BHPS and sample selection}

Given the wealth of demographic, educational and geographic information collected by the UK census, linking individual census records through time can provide insight into how individuals move through different types of neighbourhood across the life course. Such an approach is, however, constrained by the decadal intervals separating census observations. This limitation can be overcome by integrating survey data from the British Household Panel Survey with microgeographic information derived from other sources. This approach enables 
us to test a number of hypotheses linking the changing attributes and composition of households to changes of residence and the associated spatial (neighbourhood) outcomes.

This study draws on the original BHPS sample of 10,300 individuals interviewed in 1991 and tracked and re-interviewed each subsequent year until 2008 (Taylor et al., 2010). The sample also includes individuals from approximately 3,000 'booster' Scottish and Welsh households tracked from 1999 to 2008. After transforming the dataset into person-year format, one individual from each original and booster household was randomly selected in 1991 and 1999 respectively. These individuals were then tracked across all waves of the survey. Young adults living with their parents were not eligible for initial selection, as they have not been responsible for choosing their initial residential location. Following random selection, we are left with 8,421 individuals providing a nominal total of 102,331 personyears of observations. While attrition rates in the BHPS are comparatively low (Buck, 2000), the long duration of our study does mean that many of these cases are unusable due to participant dropout and occasional non-response. This could be problematic if attrition is selective, although results reported by Rabe and Taylor (2010) indicate that attrition has minimal effects upon analyses of mobility using the BHPS.

\section{Index of Multiple Deprivation}

Microgeographic information on the location of residence was then merged onto each personyear record. We rejected the use of census wards, as these are too large to approximate to neighbourhoods (cf. Bailey and Livingston, 2008). Given the devolved nature of UK administration, the available fine-scale microgeographic units differ between England/Wales and Scotland, although all are derived from the 2001 UK census. Lower Super Output Areas (LSOAs) were available for individuals in England and Wales, while the datazone (DZ) of residence was merged onto records from individuals in Scotland. Both LSOAs and DZs are constructed at a very fine scale, with LSOAs containing an average of 1,500 people (Noble et al., 2004). Measures of LSOA/DZ deprivation were then merged into the dataset. Here we draw upon the national Indices of Multiple Deprivation (IMD) produced for each devolved administration; IMD 2004 for England, SIMD 2004 for Scotland and WIMD 2005 for Wales (see Noble et al., 2004; Scottish Executive, 2004; Welsh Government, 2005). Each index is computed using information about the LSOA/DZ across six or seven 'domains' of deprivation, such as deprivation in income, employment, health and housing (see Noble et al., 2004; Scottish Executive, 2004; Welsh Government, 2005 for details). After each LSOA/DZ has been allocated a score in each domain, an overall LSOA/DZ score and relative rank position is derived by combining the weighted scores across all component domains. More deprived places are allocated higher IMD scores. An important assumption of our use of the IMD measures is that deprivation values calculated in 2004-2005 are appropriate for the entire study period (1991-2008). This may not be the case if neighbourhood attributes change rapidly, although evidence suggests that relative deprivation levels remain quite static over time (Meen et al., 2007; Meen et al., 2012). The problem of changing neighbourhood attributes is also minimised by the methods used to compute the IMD measures, as these were calculated using data collected over several years prior to publication (eg. some of the data used in calculating the IMD 2004 was gathered in 2001).

In addition to calculating a deprivation score for each LSOA/DZ, LSOA/DZs are also ranked against all others within the particular country based on their relative level of deprivation. Using these rank values enabled us to compute the relative deprivation decile of each LSOA/DZ. In this study, decile 1 contains the most deprived 10\% of LSOA/DZs within each country, while decile 10 contains the least deprived 10\%. The distribution of scores by decile for each country is presented in Table 1, with the distribution of English IMD scores by decile shown in Figure 1 (the Scottish and Welsh equivalents are highly similar). The figure shows that the more deprived the decile, the larger the range in deprivation scores within that decile.This is partly due to the methodology used to construct the IMD, but it also reflects the 
huge variation in deprivation within the most deprived decile. It is important to be aware that the construction of the IMD measures varies between countries, in terms of the component domains and how these domains are weighted, and also in terms of the scale at which the IMD is calculated (LSOA level for England/Wales, DZ for Scotland). Although this means that raw deprivation scores are not directly comparable between countries, Table 1 shows that the distribution of scores by decile does not actually differ substantially across countries. Hence we feel it is justifiable to pool observations from across the three countries when analysing changes in decile with mobility.

Table 1 The distribution of English, Scottish and Welsh deprivation scores by LSOA/DZ deprivation decile

\begin{tabular}{rrrrrrrrrr}
\hline Decile & \multicolumn{2}{c}{ English IMD 2004 scores } & \multicolumn{3}{c}{ Scottish SIMD 2004 scores } & \multicolumn{3}{c}{ Welsh WIMD 2005 scores } \\
& \multicolumn{1}{c}{ Mean } & \multicolumn{1}{c}{ Min } & \multicolumn{1}{c}{ Max } & Mean & \multicolumn{1}{c}{ Min } & Max & \multicolumn{1}{c}{ Mean } & Min & Max \\
\hline 1 & 56.36 & 45.26 & 85.59 & 57.99 & 45.53 & 87.09 & 52.85 & 42.50 & 78.90 \\
2 & 39.01 & 34.21 & 45.19 & 39.04 & 33.58 & 45.43 & 37.53 & 32.80 & 41.90 \\
3 & 30.14 & 26.61 & 34.20 & 29.80 & 26.17 & 33.48 & 29.08 & 26.40 & 32.60 \\
4 & 23.71 & 21.16 & 26.61 & 23.32 & 21.07 & 26.11 & 23.88 & 21.30 & 26.20 \\
5 & 18.94 & 17.02 & 21.15 & 18.94 & 16.96 & 21.02 & 19.45 & 17.90 & 21.20 \\
6 & 15.36 & 13.72 & 17.02 & 15.19 & 13.54 & 16.94 & 16.30 & 14.90 & 17.90 \\
7 & 12.29 & 10.96 & 13.71 & 11.85 & 10.55 & 13.49 & 13.71 & 12.40 & 14.90 \\
8 & 9.62 & 8.35 & 10.96 & 8.96 & 7.75 & 10.49 & 11.13 & 10.00 & 12.40 \\
9 & 7.03 & 5.75 & 8.34 & 6.66 & 5.38 & 7.72 & 8.37 & 7.00 & 9.90 \\
10 & 4.07 & 0.61 & 5.74 & 3.87 & 1.03 & 5.37 & 4.69 & 1.40 & 6.90 \\
Total & 21.27 & 0.61 & 85.59 & 20.71 & 1.03 & 87.09 & 21.84 & 1.40 & 78.90 \\
\hline
\end{tabular}

Source:BHPS with merged IMD data

Figure 1 Box plot of English LSOA deprivation scores by deprivation decile

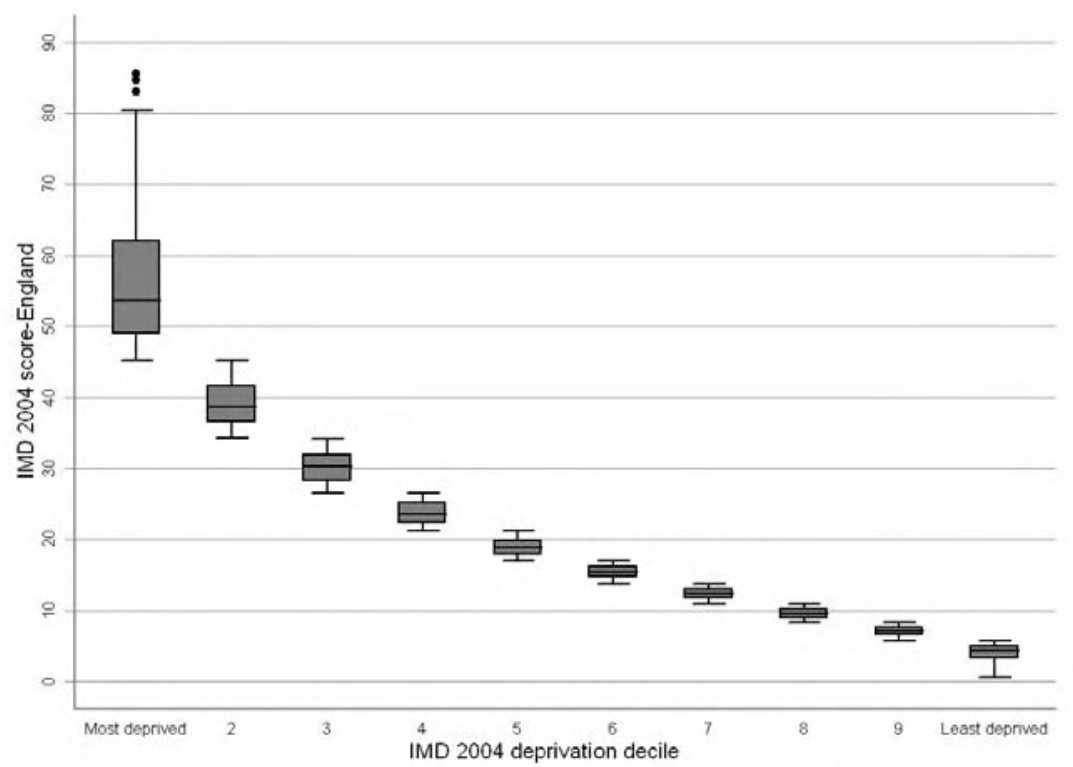

Source: BHPS with merged IMD 2004 data

Each time an individual was observed to have moved between two consecutive waves of the BHPS, we computed a change score variable by comparing the deprivation score of the origin and destination LSOA/DZ. Negative changes in score indicate improvement in neighbourhood quality, while an increase in score indicates reduced neighbourhood quality. We also observed whether the individual changed their neighbourhood deprivation decile (see Table 
2). Changes of at least 2 deciles both up and down the hierarchy were used as the dependent variables in Figures 2-5 (cells outside the grey shaded area in Table 2). In contrast, the dependent variable for the final models presented in Table 4 records whether the individual moved at least 3 decilesup or down the neighbourhood hierarchy when they changed residence.

\section{Research Findings}

Matrices of movement and stability

The pattern of movement by origin and destination for all individual move events confirms that the majority of the moves are within the same neighbourhood type, with the proportion of transitions decreasing as the difference in deprivation between the origin and destination neighbourhoods grows (Table 2). The concentration in the decile of origin varies from around 40 percent for the least advantaged neighbourhoods, to somewhat more than a third for the most advantaged areas. Overall, slightly more than one quarter of all movers stayed within the neighbourhood of origin which indicates that the middle level neighbourhoods had much lower levels of retention than either extreme. Clearly, it is the middle range of neighbourhoods that much of the movement is occurring. Overall 51.4percent of all moves were either within the neighbourhood of origin or to a neighbourhood within an adjacent decile.

Table 2 Matrix of changes in neighbourhooddecile with mobility (all selected movers known to have moved and with identified origin and destination)

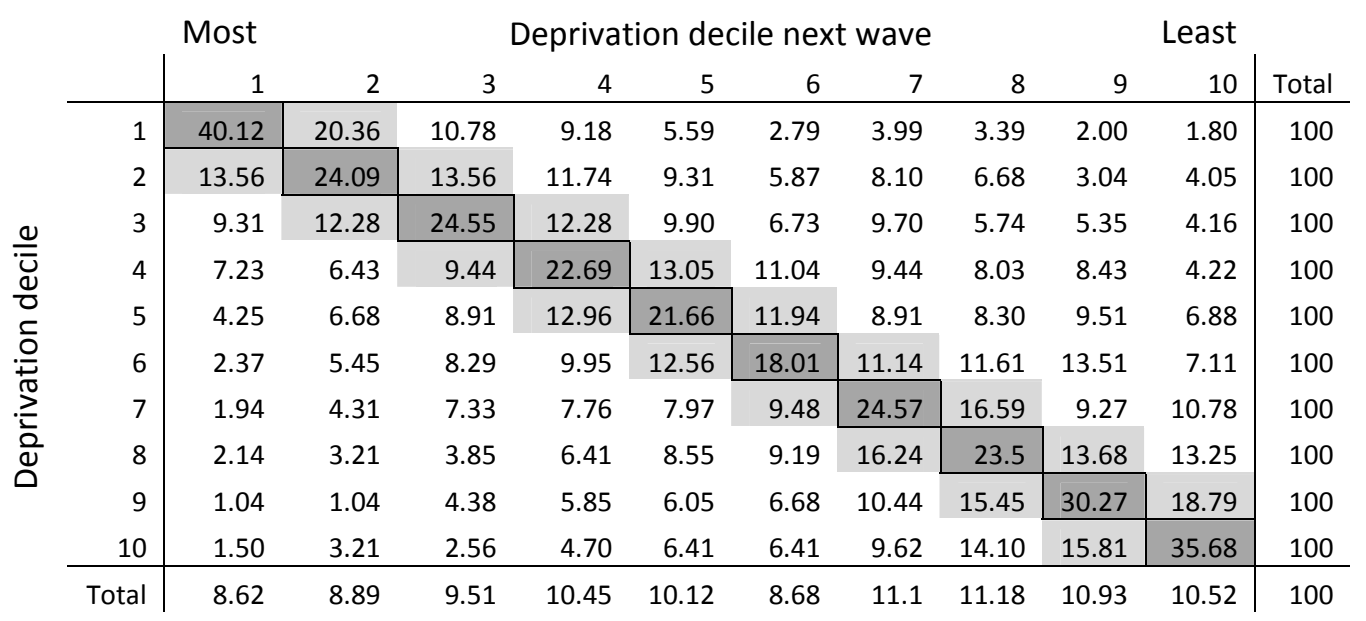

Source:BHPS 1991-2008, $n=4,793$ moves

The matrix highlights what will be a central point in our discussion, that movers from different origin neighbourhoods do not distribute themselves randomly across available destination neighbourhoods. On the contrary, the table illustrates the quite systematic relationship between the decile of destination and the decile of origin. Still, an analysis of the probabilities of movement shows that there is a significant likelihood of moving to a more advantaged neighbourhood over the course of the eighteen year period of the BHPS. For movers, there is a $41.8 \%$ chance that a move will be made to a more advantaged neighbourhood and a $31.6 \%$ chance that the move will lead to a poorer neighbourhood.In the context of "we move to improve", the data demonstrates that individuals who move typically make status gains. 
At the same time, there is clearly considerable stability in the "mobility matrix". There are large numbers of households who do not move over a very long period of time. While mobility has been the major concern of studies of social change, the other side of the coin, the non-mobile, has been given less attention, although it is this issue of stability which may be most critical in understanding the amount of social change which occurs in a society. People who move locally, but donot change neighbourhood type, and those who do not move at all, are together a measure of the lack of dynamism in the system.

From a longer term perspective over the whole 18 wave period, how "sticky" are neighbourhood types? That is, how likely are individuals to stay in the same neighbourhood deprivation decile for long periods of time (regardless of whether or not they churn within it)? Using the BHPS, the estimation of duration is only possible for full records. Unfortunately, the data includes a large number of censored records, due to individuals dying or leaving the sample. For the remaining full (18 year) records and excluding the booster sample members, we found that on average individuals live about8-12 years in thedecile in which they were observed in 1991, with the 75 percentileclose to 20 years (results not shown). A not insignificant number of people have been in the same decile for most of their residential careers. The data does not show much variation across the deciles. This suggests that the duration of residence does not vary in any significant way from decile to decile. When we introduce age there is some variation across deciles. As we expect, the mean length of duration increases with age,as does the variability of duration.

\section{Changing neighbourhood locations}

The previous section focused on the aggregate movements of individuals between different types of neighbourhoods. In this section we unpack those aggregate changes,to see whether three of the important determinants of mobility behaviour - age, income and housing tenurestructure the neighbourhood outcomes of moves. In the following discussion it is important to keep in mind that there is of course a structural constraint in the movements across neighbourhood types. A household or individual in the most advantaged group of neighbourhoods can only remain where they are or move to neighbourhoods which are less advantaged, and, as a corollary, households or individuals in the least advantaged neighbourhoods can only increase their status or remain where they are. To move beyond the significant tendency to remain in the neighbourhood of origin or a nearby neighbourhood we therefore define change as a movement of at least two deciles in status.

Figure 2 Frequency of moves up and down the neighbourhood hierarchy by deprivation decile of origin neighbourhood

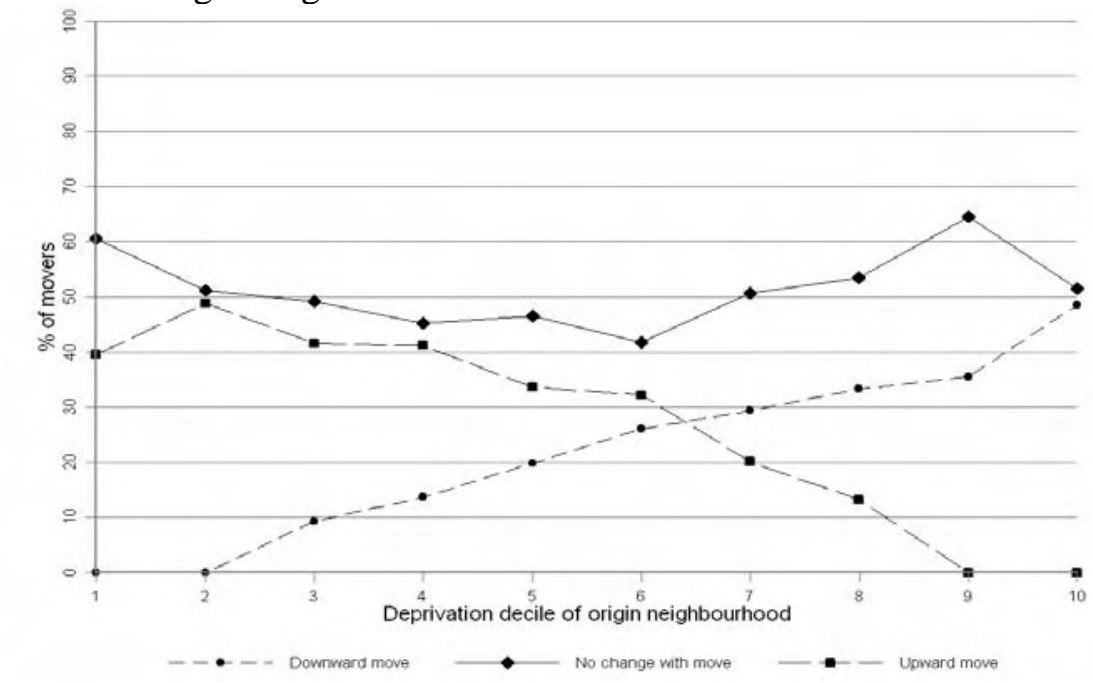

Source: BHPS 1991-2008 
Figure 2 shows the frequency of moves up and down the neighbourhood hierarchy by deprivation decile of the neighbourhood of origin. The figure demonstrates the propensity for individuals not to change neighbourhood type when they move, as well the structural effects at each end of the diagram. The very least advantaged deciles have strong capturing affects: fifty to sixty percent of those in the least advantaged collection of neighbourhoods do not make a change in status when they move. At the other extreme, very few of those in the most advantaged areas move down in status. More than $50 \%$ of those in the most advantaged areas move within one decile of their origin, while nearly $65 \%$ of those in decile 9 move to deciles 8,9 or 10 .

\section{Age structures of mobility and migration}

Younger individuals and households move significantly more often than do older households. But although age is clearly a defining characteristic for the probability of moving, it is less a determinant for the probability of moving up or down in status, as the differences across age are muted (see Figure 3a and b). Still there are expected outcomes. Younger individuals are likely to move to more advantaged neighbourhoods and older individuals in the middle ranges of advantage (deciles 5 and 6) are more likely to move up and less likely to move down. Clearly their life course trajectory is still one of upward mobility in the housing market.

Figure 3aThe percentage of movers by age category and deprivation decile of origin who move to a more deprived neighbourhood

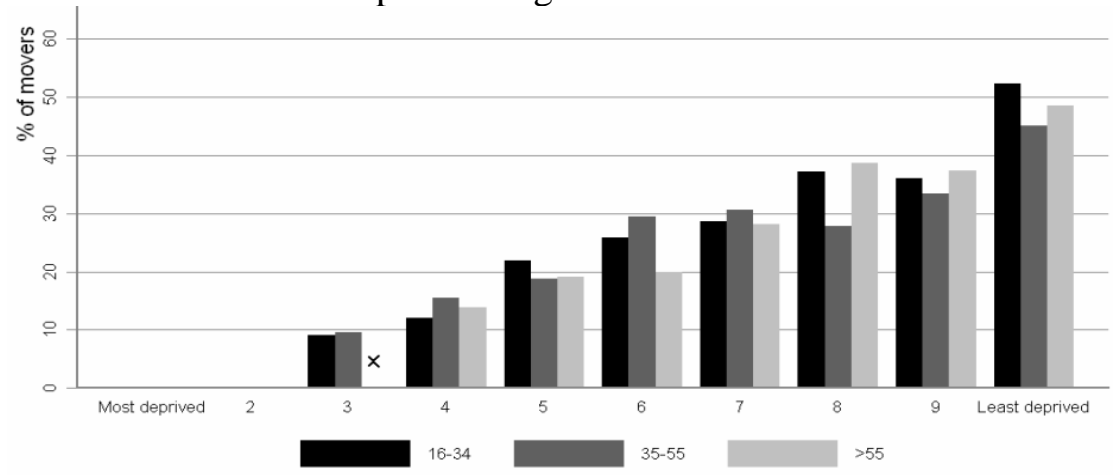

Note: bars removed and marked with a cross if <15 cases (same for further graphs)

Figure 3bThe percentage of movers by age category and deprivation decile of origin who move to a less deprived neighbourhood

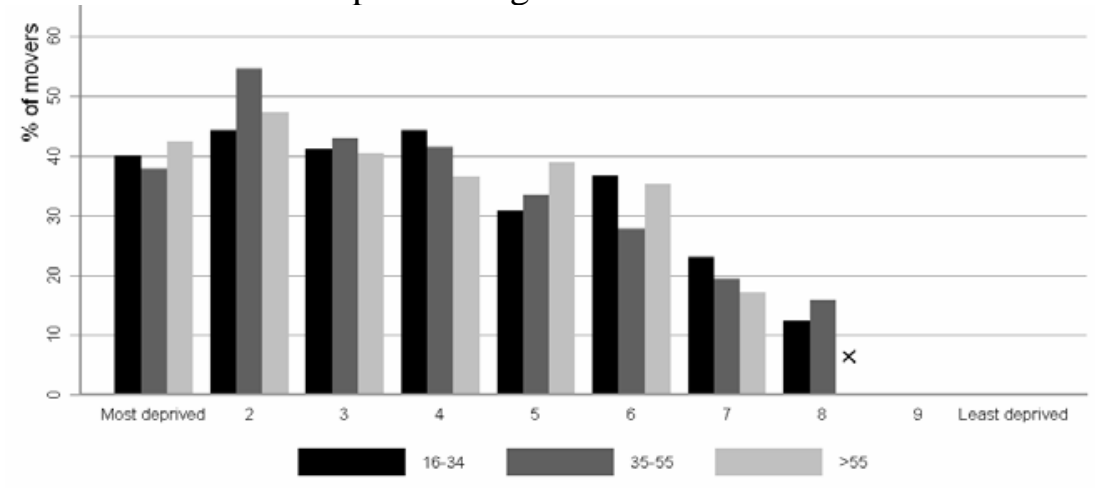

Source:BHPS 1991-2008

While age has a rather muted impact, the same is not true for income (Figures $4 \mathrm{a}$ and $\mathrm{b}$ ). Individuals in the lowest quartile of household incomes are significantly more likely to move 
to more disadvantaged areas.In contrast, higher incomes provide the opportunity to move up or maintain higher level status. Some of the bars in the histogram are based on small numbers (if numbers were too small they have been crossed-out), but overall the pattern is still quite clear. Very few top income quartile households move to very disadvantaged neighbourhoods. This finding is not surprising, but it reiterates the structural difficulty for lower income households to make anything but marginal gains in neighbourhood quality when they move.

Tenure and income are related and the outcomes across tenure reinforce the effect of socio-economic status on residential relocations (Figures $5 \mathrm{a}$ and b). Again the extremes have relatively small samples (eg very few social renters live and move within the least deprived deciles), but the overall pattern is clear. Homeowners are able to move out of less advantaged areas and social renters are likely to move out of the least deprived areas and down the socioeconomic scale. It appears that social renters, even if they live initially in more advantaged neighbourhoods, are unable to maintain their status in such neighbourhoods when they move. This is likely to be due to the relative concentration of socially rented properties in less desirable locations.

Figure 4a The percentage of movers in the lowest and highest income quartiles by deprivation decile of origin who move to a more deprived neighbourhood

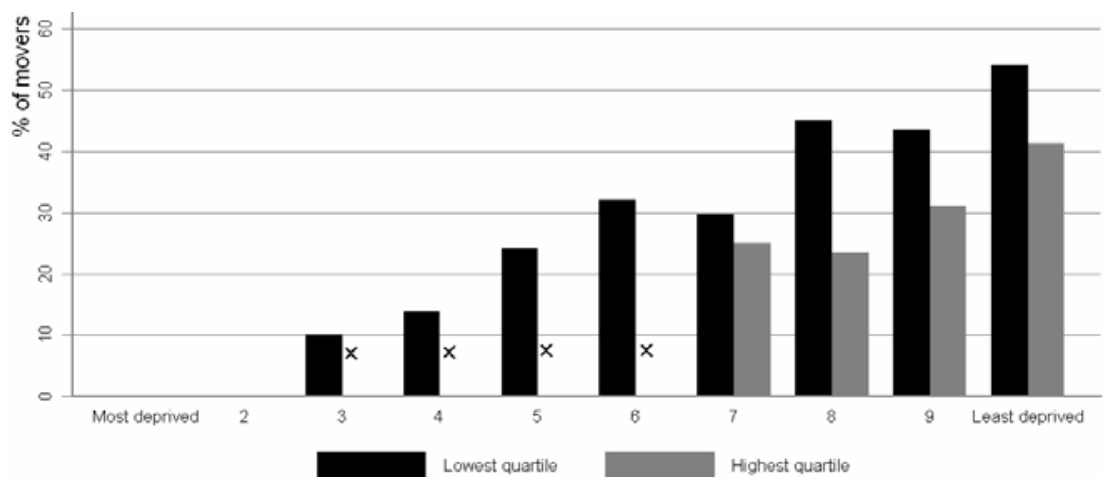

Figure 4b The percentage of movers in the lowest and highest income quartiles by deprivation decile of origin who move to a less deprived neighbourhood

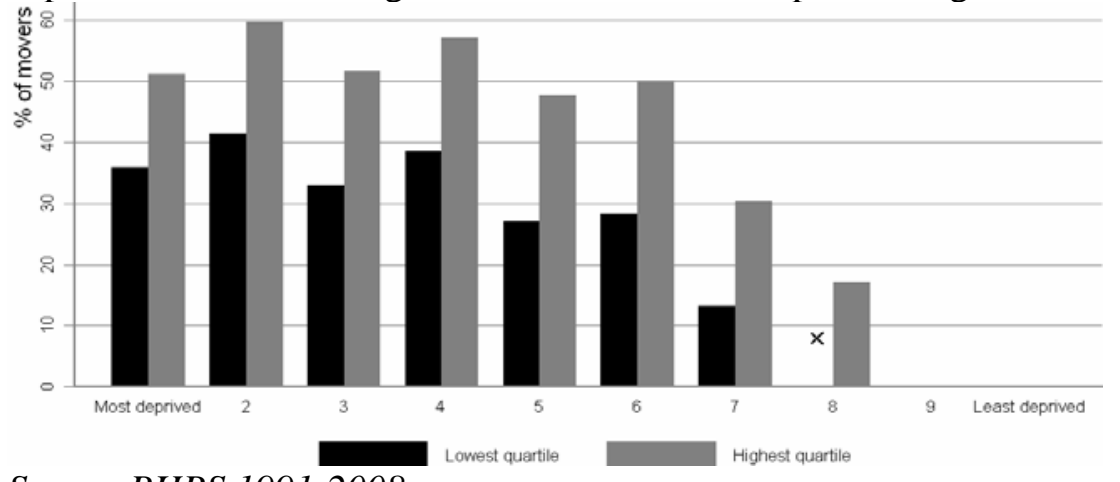

Source:BHPS 1991-2008 
Figure 5aThe percentage of movers by housing tenure and deprivation decile of origin who move to a more deprived neighbourhood

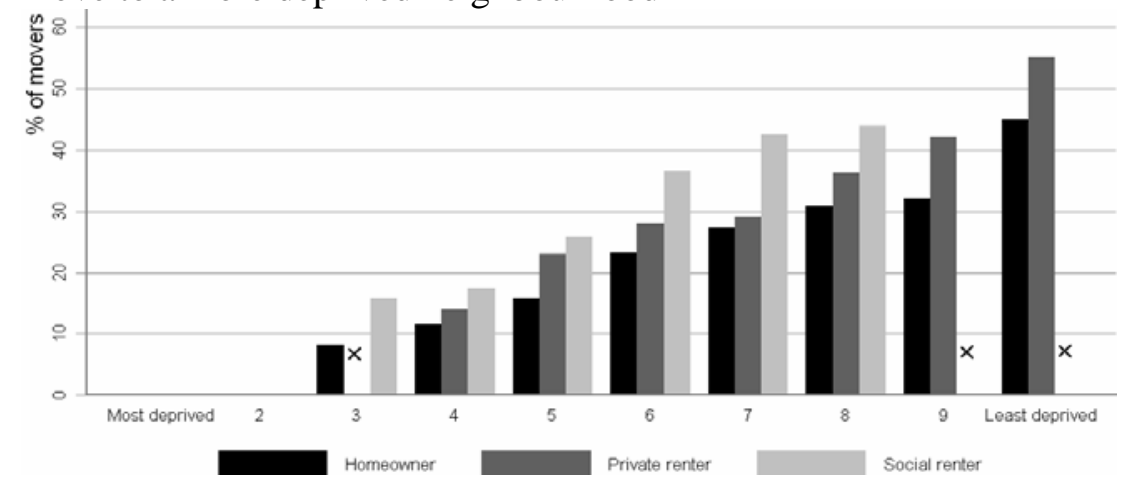

Figure 5bThe percentage of movers by housing tenure and deprivation decile of origin who move to a less deprived neighbourhood

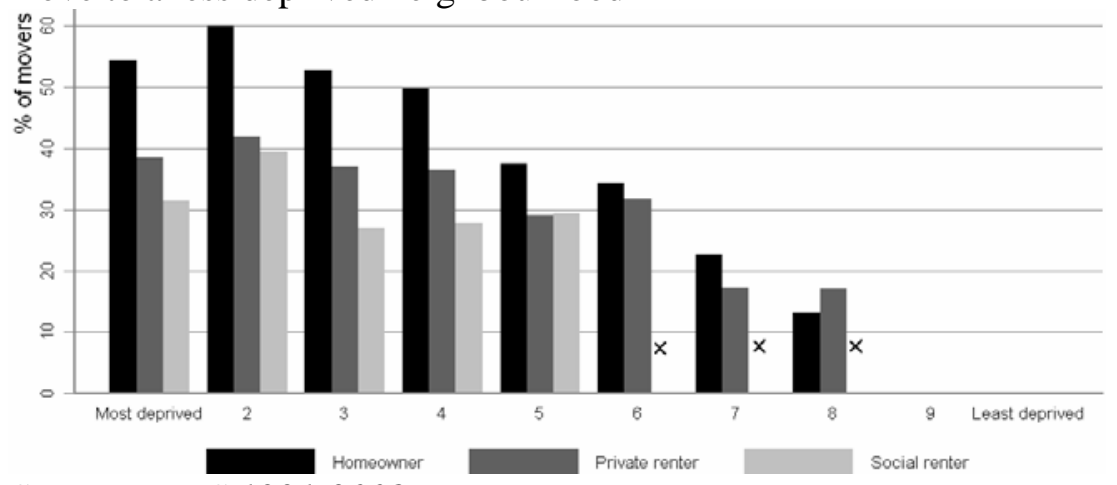

Source:BHPS 1991-2008

\section{Mobility and changing deprivation scores}

The analysis has to this point focused on the changes in deprivation decile which can occur with mobility. We now turn to investigate changes in the LSOA/DZ scores. When an individual moves from one neighbourhood to another there is an associated change in their deprivation score. We can derive this change score value $\left(\Delta S_{i j}\right)$ by subtracting the origin neighbourhood score $\left(\mathrm{S}_{\mathrm{i}}\right)$ from the destination neighbourhood score $\left(\mathrm{S}_{\mathrm{j}}\right)$ Hence:

$$
\Delta \mathrm{S}_{\mathrm{ij}}=\mathrm{S}_{\mathrm{j}}-\mathrm{S}_{\mathrm{i}}
$$

Thisscore change can be quite modest and in such cases, the household or individual is likely to move within the current decile category. Over all the waves of the BHPS, the changes in deprivation scores range from about -60 points to +60 points, with the majority of changes clustered in the range of -10 to +10 . Indeed, approximately half of all moves generate a score change between -8 and +5 .

To understand the effect of neighbourhood of origin on subsequent mobility outcomes, we model the relationship between the change in the IMD score with a move using the IMD score at the neighbourhood of origin as the sole independent variable. We present pooled scatterplots of this relationship (for the whole of the UK) (Figures 6a and 6b). In each of the two scatter plots we have superimposed the decile boundaries (for England only) that were the definitions for the matrices of movement discussed earlier. Because of the nature of the neighbourhood scores, a move from a less advantaged neighbourhood to a more advantaged neighbourhood will reduce the score change value.The line at $Y=0$ separates movers according to whether they moved to a neighbourhood that ranked higher or lower than the one they left. 
In general, the plots show that those movers who begin in better neighbourhoods tend to move 'down' (increasing their neighbourhood deprivation as the Y label indicates). In contrast, those leaving less advantagedneighbourhoods are more likely to move 'up' to (slightly) less deprived neighbourhoods.

Given that income and housing tenure structure the neighbourhood changes which occur with mobility, we have estimated separate regression lines for income and tenure groups and displayed these on the scatterplots. These are the downward sloping lines on the graphs, with the narrow shading around the line indicating the confidence intervals of the estimate. There is evidence that these relationships are somewhat nonlinear, so we estimate the lines using the equation:

$$
\Delta S_{i j}=\alpha+\beta_{1} S_{i}+\beta_{2} S_{i}^{2}
$$

We can interpret the slope of the lines as a measure of the ability to move across the urban structure defined by deciles of advantage and disadvantage If there was no slope then there would be no socio-spatial mobility, i.e. no difference across the distribution of scores. Of course the slopesare a measure of the ability to change location without controlling for confounding individual or household characteristics. The slopes indicate that the rate of upward mobility increases with lower levels of disadvantage. For income, the slopes of the lines are significantly different (Figure 6a). The steeper regression line for the highest income quartile demonstrates that high levels of income have a powerful effect on enabling moves to more advantaged places. For tenure, the relatively flat line for social renters reflects the income effect and possibly the more constrained choice set available to social renters (Figure $6 b)$. We have omitted private renters from the graph because the confidence intervals clearly overlap with those of homeowners and social renters. The regression line for private renters is highly curvilinear, suggesting accelerating improvements with increasing deprivation, possibly as these individuals are moving into homeownership.

Now we model mobility while controlling for the intervening variables of age, income, tenure and education which underlie the process of social mobility.

Figure 6aChange in deprivation score by deprivation score of origin neighbourhood for the lowest and highest income quartiles (pooled countries with English decile lines)

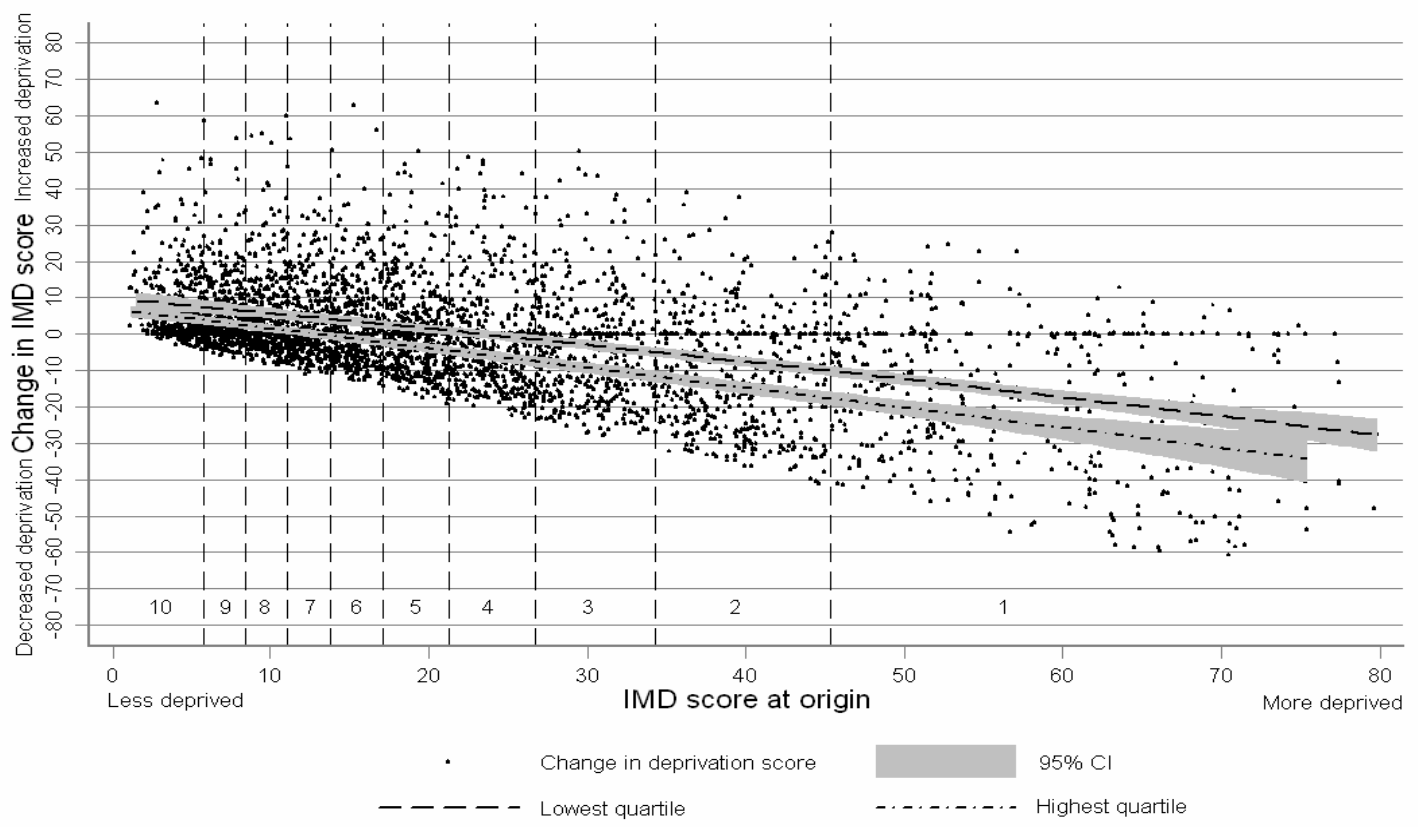


Figure 6bChange in deprivation score by deprivation score of origin neighbourhood and housing tenure (pooled countries with English decile lines)

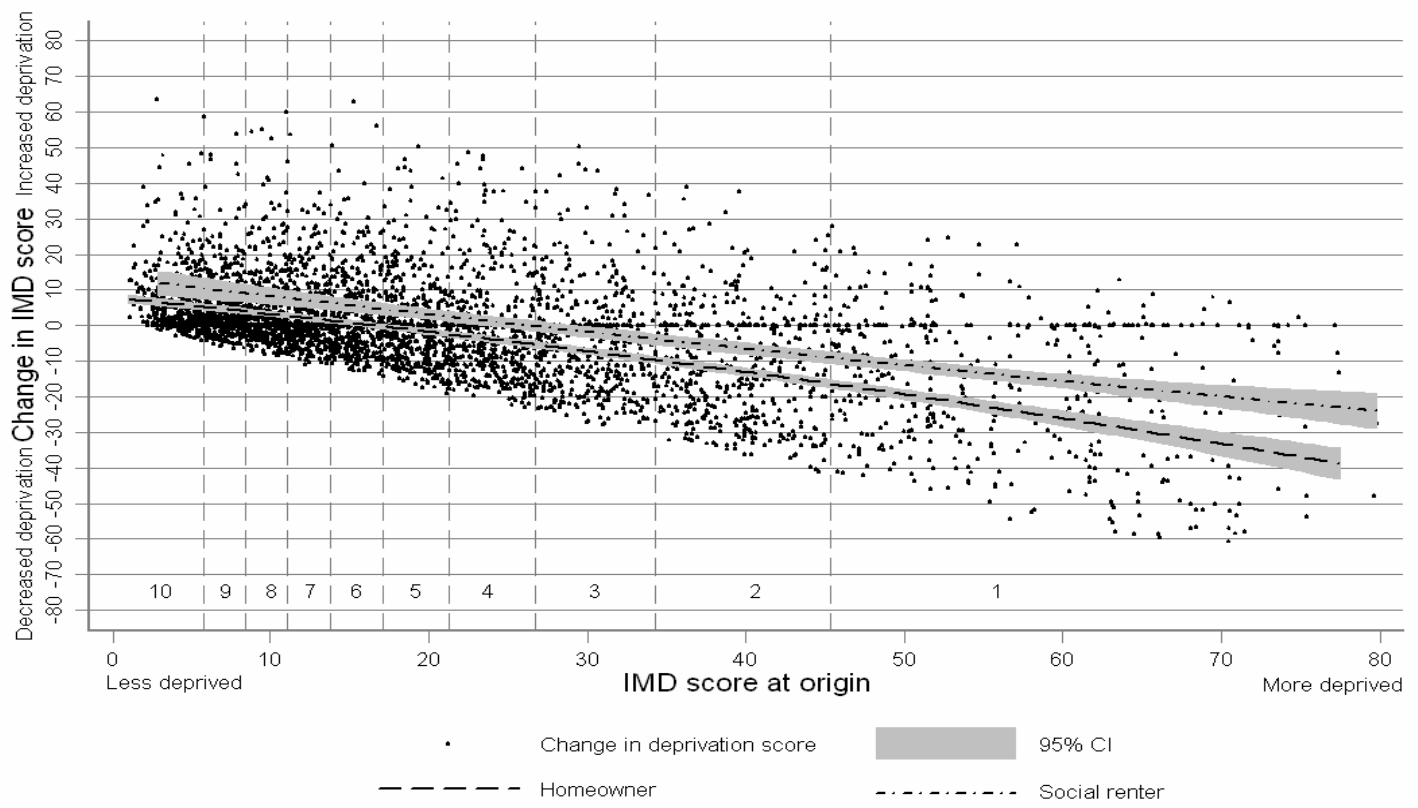

Note: Error introduced to protect the confidentiality of survey participants Source:BHPS 1991-2008

\section{Models of sorting and residential change}

How much does the place of origin affect the likelihood and degree of social mobility? To uncover the effect of place and household and individual characteristics on social mobility we construct a series of models which successively incorporate additional household and individual characteristics.

We estimate a model in which the changes in neighbourhood deprivation scores experienced by movers are regressed on the score at origin, with mover attributes being added successively to reflect the role of age, family composition, education, employment, and tenure (Table 3). The first coefficient in the equation measures the influence of the mover's neighbourhood of origin on the change in the neighbourhood score as they move from one neighbourhood to another.The additional coefficients reflect the effect of individual variables as they are entered into the model.Of specific interest is the way in which those estimates change as successive control variables are entered.

The first observation is that our measurement of socio-spatialmobility is captured by the change in the coefficient of the score at the origin (remember that the highest IMD score reflects the most deprived neighbourhoods). Thus, the differences between the Model 1 score (-.513-1.0) and the score in Model 6 (-.581-1.0) is a measure of the amount of upward movement in the system. Hence the first point of interest is the way in which the deprivation score of the neighbourhood of origin is associated with the degree of socio-spatialmobility. What the change in the first coefficient across the six models suggests therefore, is that the influence on the ability to change level of deprivation, which we might otherwise attribute to the statuslevel of theneighbourhood of origin, is reduced by the controls for age, household composition, education and income. That the coefficient remains significant tells us that where one starts clearly matters.

The influence of the individual attributes entered successively in the models in Table 3 allows us to measure the individual effects on neighbourhood outcomes. The models successively enter variables which capture the effects of age and ethnicity (model 2), household type (model 3), education (model 4), employment status and income (model 5), 
and tenure (model 6).Significantly, age does not appear to provide additional explanation for the movement between deprivation areas (as was evident from Figures 3a and b).Gender has a modest initial effect, but this vanishes in successive models.Initially in model 3 household type is significant but the effect is quite reduced in successive models. Still, lone parent families have significant effects: the positive coefficient indicates that being a lone parent increases the IMD score of the neighbourhood after moving, equalling a drop in neighbourhood status. Lone parents typically experience reductions in neighbourhood quality when they move.

The power of the models and the greatest sustaining explanation is the successive effects of education, income and housing tenure.Education remains significant across models 4-6 and employment status also plays an important predictive role in the likelihood of moving from one area to another,a movement which is in general upward (the coefficients are negative).The unemployed are, however, likely to move to or remain in more deprived areas. The highest income quartile is significantly likely to move up the neighbourhood hierarchy, as we demonstrated earlier in the descriptive analyses. Finally, households in the social rented sector and even private renters are significantly likely to "move down" socially, in the sense of their movement across the neighbourhood deprivation structure.

While the results from the models provide considerable insight on the forces behind moves up and down the hierarchy of deprivation scores, we can add considerable additional insight by examining moves which are of at least three deciles up or down the decile hierarchy. Additionally, we limit the origins to the groups of the upper three deciles, the lower three deciles and the middle deciles (4-7). Thus, we examine the moves of at least three decilesup from the lowest three deciles (models 7-8), moves down of at least three deciles from the top three deciles (models 9-10), and the moves either up (not shown) or down (model 11) three deciles from the middle four deciles.

The logit models of a move up (or down) are estimated as functions of age, family structural change, education level, employment status change, and income level. We introduced these variables sequentially to examine their predictive power on the likelihood of change. We also introduced outcome measures of tenure.Thus, we examine how the variables influence the likelihood of change and the outcome in the housing market as a result of moving significantly up or down the neighbourhood hierarchy.

Factors influencing moves up from the lowest three decilesare older age, higher education and higher income (Model 7).In contrast, factors influencing moves down from the highest decilesare young age, being single, having a low education,and moving into unemployment (Model 9). These effects are however considerably reduced and often rendered insignificant when we add housing tenure change variables (Models 8 and 10). The housing market and where you are in it are critical elements on the process of socio-spatial mobility. Those who stay or move into social renting are least likely to move up the neighbourhood hierarchy, and the most likely to move down the neighbourhood hierarchy. Again, this suggests that the location of socially rented properties structures the neighbourhood outcomes of movers within the social sector.

For the middle deciles, education and income are the drivers for upward moves (not shown),a process not dissimilar to the moves out of the lowest deciles, and the outcome is negatively related to social renting. For households that move down three deciles(model 11) we see the effect of family structure change.Changing partners and divorce, moving from a union to single status are significant explanations for moving down the social scale. Those who move from ownership to social rent, but also from private rent to own are the most likely to move down the neighbourhood hierarchy. 
Table 3 Random effects linear regression estimates of the change in deprivation score with a move

\begin{tabular}{|c|c|c|c|c|c|c|c|c|c|c|c|c|}
\hline & \multicolumn{2}{|l|}{ Model 1} & \multicolumn{2}{|l|}{ Model 2} & \multicolumn{2}{|l|}{ Model 3} & \multicolumn{2}{|l|}{ Model 4} & \multicolumn{2}{|l|}{ Model 5} & \multicolumn{2}{|l|}{ Model 6} \\
\hline & Coeff & se & Coeff & se & Coeff & se & Coeff & se & Coeff & se & Coeff & se \\
\hline IMD score of origin & $-0.513 * * *$ & 0.012 & $-0.518 * * *$ & 0.012 & $-0.522 * * *$ & 0.012 & $-0.543 * * *$ & 0.013 & $-0.555 * * *$ & 0.013 & $-0.581 * * *$ & 0.013 \\
\hline Age & & & -0.105 & 0.065 & -0.083 & 0.066 & -0.088 & 0.066 & 0.041 & 0.067 & 0.067 & 0.068 \\
\hline $\mathrm{Age}^{2}$ & & & 0.001 & 0.001 & 0.001 & 0.001 & 0.001 & 0.001 & -0.001 & 0.001 & -0.001 & 0.001 \\
\hline Female & & & $0.833^{*}$ & 0.408 & 0.385 & 0.415 & 0.325 & 0.414 & 0.108 & 0.416 & 0.276 & 0.415 \\
\hline Ethnic minority & & & 1.550 & 1.180 & 1.366 & 1.173 & 1.141 & 1.161 & 0.528 & 1.147 & 0.046 & 1.147 \\
\hline \multicolumn{13}{|c|}{ Household type (ref couple) } \\
\hline Single & & & & & $1.835^{*}$ & 0.561 & $1.961 * * *$ & 0.564 & 0.763 & 0.594 & 0.560 & 0.592 \\
\hline Couple \& children & & & & & $1.209 *$ & 0.516 & 0.895 & 0.518 & $1.112^{*}$ & 0.515 & 0.887 & 0.517 \\
\hline Lone parent & & & & & $4.077 * * *$ & 0.718 & $3.822 * * *$ & 0.724 & $2.676^{* * *}$ & 0.732 & $2.030 *$ & 0.736 \\
\hline Other & & & & & $2.699 *$ & 0.995 & $2.507^{*}$ & 0.995 & $2.454^{*}$ & 0.990 & $2.309 *$ & 0.992 \\
\hline \multicolumn{13}{|c|}{ Education level (ref very low) } \\
\hline Low & & & & & & & $-3.265 * * *$ & 0.600 & $-2.787 * * *$ & 0.597 & $-2.453 * * *$ & 0.599 \\
\hline Medium & & & & & & & $-4.515^{* * *}$ & 0.564 & $-3.423 * * *$ & 0.571 & $-2.816^{* * *}$ & 0.577 \\
\hline High & & & & & & & $-5.587 * * *$ & 0.711 & $-3.554 * * *$ & 0.734 & $-2.943 * * *$ & 0.741 \\
\hline \multicolumn{13}{|c|}{ Employment status (ref employed) } \\
\hline Unemployed & & & & & & & & & $3.322 * * *$ & 0.970 & $2.957^{*}$ & 0.968 \\
\hline Inactive & & & & & & & & & $2.003^{* * *}$ & 0.530 & $1.709 *$ & 0.529 \\
\hline \multicolumn{13}{|c|}{ Household income quartile (ref lowest) } \\
\hline 2 & & & & & & & & & -0.462 & 0.561 & 0.175 & 0.567 \\
\hline 3 & & & & & & & & & $-2.173 * * *$ & 0.624 & -1.192 & 0.636 \\
\hline Highest & & & & & & & & & $-3.914 * * *$ & 0.692 & $-2.989 * * *$ & 0.704 \\
\hline \multicolumn{13}{|c|}{ Housing tenure (ref owner) } \\
\hline Social renter & & & & & & & & & & & $4.228 * * *$ & 0.576 \\
\hline Private renter & & & & & & & & & & & $1.559 *$ & 0.513 \\
\hline \multicolumn{13}{|l|}{ Nation (ref England) } \\
\hline Wales & & & & & & & & & & & -0.501 & 0.602 \\
\hline Scotland & & & & & & & & & & & $-1.275^{*}$ & 0.516 \\
\hline Constant & $9.714 * * *$ & 0.331 & $11.439 * * *$ & 1.630 & $9.751 * * *$ & 1.700 & $14.884 * * *$ & 1.794 & $12.875 * * *$ & 1.817 & $11.081 * * *$ & 1.874 \\
\hline Rho & 0.105 & & 0.099 & & 0.093 & & 0.077 & & 0.060 & & 0.059 & \\
\hline $\mathrm{Chi}^{2}$ & 1838.423 & & 1828.450 & & 1864.841 & & 1895.678 & & 1963.822 & & 2014.647 & \\
\hline $\mathrm{N}$ & 4655 & & 4550 & & 4550 & & 4442 & & 4424 & & 4391 & \\
\hline
\end{tabular}

$* * *=p<0.001 *=p<0.05$ (model $v$ similar if we just use an OLS with clustered S.Es- $r^{2}$ of these OLS regressions improves from 0.25-0.29 during buildup)

Source: BHPS 1991-2008 
Table 4Random effects logistic regression models of the propensity for movers from the bottom 3 deciles to move up at least 3 deciles when they move (model 7-8), from the top three deciles to move down at least 3 deciles (models 9-10), and from the middle 4 deciles to move downat least 3 deciles (model 11). Reference=remain within 3 deciles of origin after moving

\begin{tabular}{|c|c|c|c|c|c|c|c|c|c|c|}
\hline & \multicolumn{4}{|c|}{ Bottom 3 deciles move } & \multicolumn{4}{|c|}{ Top 3 deciles move } & \multicolumn{2}{|c|}{ Middle 4 deciles move } \\
\hline & \multirow{2}{*}{$\begin{array}{c}\text { Model } 7 \\
\text { Coeff }\end{array}$} & & Model 8 & & \multicolumn{2}{|l|}{ Model 9} & \multirow{2}{*}{$\begin{array}{c}\text { Model } 10 \\
\text { Coeff }\end{array}$} & \multicolumn{3}{|c|}{ Model 11} \\
\hline & & se & Coeff & se & Coeff & se & & se & Coeff & se \\
\hline Age & $0.016^{*}$ & 0.006 & 0.012 & 0.006 & $-0.013^{*}$ & 0.006 & $-0.014^{*}$ & 0.007 & -0.003 & 0.006 \\
\hline \multicolumn{11}{|c|}{ Marital status change $t$ to $t+1$ (ref remained couple) } \\
\hline Single-single & -0.325 & 0.178 & -0.271 & 0.185 & $0.659 * * *$ & 0.196 & $0.414 *$ & 0.200 & 0.068 & 0.198 \\
\hline Changed partner & 0.058 & 0.679 & 0.115 & 0.677 & 0.925 & 0.539 & 0.948 & 0.553 & $1.208^{*}$ & 0.528 \\
\hline Single-union & -0.494 & 0.279 & -0.544 & 0.284 & 0.490 & 0.263 & 0.292 & 0.267 & 0.370 & 0.270 \\
\hline Union-single & -0.575 & 0.305 & -0.447 & 0.324 & -0.017 & 0.331 & -0.235 & 0.341 & $0.674 *$ & 0.292 \\
\hline \multicolumn{11}{|c|}{ Change in $n$ children $t$ to $t+1$ (ref none-none) } \\
\hline Same $n$ children & -0.197 & 0.187 & -0.029 & 0.196 & -0.330 & 0.196 & -0.366 & 0.198 & -0.024 & 0.196 \\
\hline Increased n children & -0.213 & 0.285 & -0.174 & 0.293 & -0.018 & 0.317 & -0.143 & 0.326 & -0.283 & 0.339 \\
\hline Decreased $n$ children & -0.608 & 0.352 & -0.505 & 0.362 & -0.211 & 0.354 & -0.433 & 0.371 & $-0.828 *$ & 0.364 \\
\hline \multicolumn{11}{|c|}{ Education level (ref v low) } \\
\hline Low & $0.654^{*}$ & 0.208 & $0.519 *$ & 0.216 & -0.412 & 0.256 & -0.334 & 0.269 & -0.006 & 0.235 \\
\hline Medium & $0.788^{* * *}$ & 0.215 & $0.570^{*}$ & 0.220 & $-0.490 *$ & 0.235 & -0.311 & 0.250 & 0.094 & 0.228 \\
\hline High & $0.808^{*}$ & 0.291 & $0.725^{*}$ & 0.303 & $-0.725 *$ & 0.276 & -0.539 & 0.290 & 0.170 & 0.297 \\
\hline \multicolumn{11}{|c|}{ Employment status change (ref emp-emp) } \\
\hline Unemp-unemp & -0.897 & 0.524 & -0.615 & 0.532 & 0.771 & 0.691 & 0.440 & 0.692 & 0.286 & 0.541 \\
\hline Inactive-inactive & -0.379 & 0.203 & -0.150 & 0.212 & 0.248 & 0.225 & 0.145 & 0.229 & -0.095 & 0.236 \\
\hline Into work & -0.180 & 0.328 & -0.081 & 0.339 & 0.449 & 0.324 & 0.473 & 0.327 & -0.234 & 0.408 \\
\hline Into unemp & -0.171 & 0.352 & -0.099 & 0.365 & $1.074 *$ & 0.530 & 0.952 & 0.528 & 0.502 & 0.397 \\
\hline Into inactivity & -0.161 & 0.336 & -0.027 & 0.367 & 0.369 & 0.332 & 0.352 & 0.336 & 0.292 & 0.310 \\
\hline \multicolumn{11}{|c|}{ Household income quartile (ref lowest 25\%) } \\
\hline 2 & 0.084 & 0.185 & -0.100 & 0.196 & 0.101 & 0.230 & 0.170 & 0.243 & 0.040 & 0.225 \\
\hline 3 & $0.706 *$ & 0.224 & 0.378 & 0.239 & 0.009 & 0.239 & 0.166 & 0.252 & 0.273 & 0.236 \\
\hline Highest & $0.759 *$ & 0.274 & 0.359 & 0.289 & -0.232 & 0.246 & -0.129 & 0.262 & -0.394 & 0.292 \\
\hline \multicolumn{11}{|c|}{ Change in housing tenure (ref own-own) } \\
\hline S.rent-s.rent & & & $-1.447 * * *$ & 0.244 & & & $1.260 *$ & 0.386 & $0.923 * * *$ & 0.264 \\
\hline P.rent-p.rent & & & $-0.737^{*}$ & 0.279 & & & 0.226 & 0.285 & 0.435 & 0.274 \\
\hline Own-s.rent & & & $-1.777^{* * *}$ & 0.470 & & & $1.603 * * *$ & 0.481 & $1.477^{* * *}$ & 0.318 \\
\hline Own-p.rent & & & -0.348 & 0.331 & & & $0.545^{*}$ & 0.237 & 0.137 & 0.289 \\
\hline S.rent-own & & & -0.512 & 0.298 & & & 0.014 & 0.769 & -1.019 & 0.742 \\
\hline S.rent-p.rent & & & -0.553 & 0.315 & & & 0.328 & 0.744 & 0.834 & 0.606 \\
\hline P.rent-own & & & $-0.630 *$ & 0.294 & & & -0.133 & 0.266 & $0.659 *$ & 0.257 \\
\hline P.rent-s.rent & & & $-2.478 * * *$ & 0.537 & & & 0.535 & 0.497 & 0.765 & 0.393 \\
\hline Constant & $-1.742^{* * *}$ & 0.389 & -0.814 & 0.428 & -0.275 & 0.433 & -0.454 & 0.479 & $-2.335^{* * *}$ & 0.493 \\
\hline Rho & 0.208 & & 0.190 & & 0.198 & & 0.166 & & 0.029 & \\
\hline Log likelihood & -849.869 & & -769.295 & & -761.896 & & -710.406 & & -620.319 & \\
\hline $\mathrm{Chi}^{2}$ & 65.778 & & 88.770 & & 45.492 & & 58.168 & & 58.775 & \\
\hline Degrees of freedom & 19 & & 27 & & 19 & & 27 & & 27 & \\
\hline $\mathrm{N}$ & 1430 & & 1366 & & 1340 & & 1282 & & 1696 & \\
\hline
\end{tabular}




\section{Conclusions and Observations}

There is an enduring concern with opportunity structures in society. We believe, probably correctly, that a society which provides opportunities for individuals to move up the social, occupational and economic ladders is a society which is more egalitarian than a society which provides barriers and constraints to movement through the social hierarchy. But, even if there are no formal barriers, how is mobility constrained by who you are and where you live? This has been the concern of this paper.

The results of our analysis extend in much greater detail previous work on the process of movement across the socio-spatial hierarchy. Previously the focus was on the difficulty of leaving poor neighbourhoods and studies in generalfocusedon those in poverty and in poor neighbourhoods (eg Robson et al., 2008). Our models, which cover the entire spectrum of neighbourhoods, provide a much fuller interpretation of the process of mobility across sociospatial structures.We find perhaps not surprisingly, that education and income matter for the propensity tomake socio-spatial gains with mobility, while family structural change leads to downward movement for those in the middle levels of the hierarchy. Younger and single person households appear at the greatest risk of moving down out of the top deciles of the neighbourhood hierarchy.

The two most significant findings are that both neighbourhood and housing tenure clearly structure the neighbourhood outcomes associated with residential moves. Both findings clearly indicate structural inequality in British society. Those living at the bottom of the neighbourhood hierarchy have real difficulty in advancing their socio-spatial position through mobility, especially when combined with job loss and low education levels. Tenure changes are the most important and significant predictors of neighbourhood mobility. Becoming a social renter almost by definition means moving down the neighbourhood hierarchy. Those who are forced to live in the tenure of last resort are penalised by also being forced into the most deprived, and opportunity poor communities. If one believes in neighbourhood effects, then the poor are disadvantaged both by being poor and through their tendency to end up in the most disadvantaged places.

Although beyond the scope of this paper, it is an important to consider whether this finding is specific to the UK context. In other countries with different welfare regimes, such as the Netherlands, social renting is less stigmatised and less residualised. It can be expected that in the Netherlands, and countries with similar tenure structures, moving into social renting is less associated with moving down the neighbourhood hierarchy. If this is the case, how does this reflect on the social structure of British society, and opportunities for social mobility? The results suggest that in the UK the socio-spatial hierarchy, and the opportunities to move to better places, is highly stratified by housing tenure.

\section{Acknowledgement}

We gratefully acknowledge financial support from the Economic and Social Research Council (ESRC) (REF-074270020) which made possible a 2-month guest Professorship of Bill Clark at the University of St Andrews.

\section{Disclaimer}

The data used in this study were made available through the ESRC Data Archive. The data were originally collected by the ESRC Research Centre on Micro-Social Change at the

University of Essex (now incorporated within the Institute for Social and Economic 
Research). Neither the original collectors of the data nor the Archive bear any responsibility for the analyses or interpretations presented here.

\section{References}

Bailey, N. and M. Livingston (2008) Selective migration and area deprivation: evidence from 2001 census migration data for England and Scotland. Urban Studies 45(4), 943-961.

Bolt, G., R. van Kempen, van Ham, M. (2008) Minority ethnic groups in the Dutch housing market: spatial segregation, relocation dynamics and housing policy. Urban Studies 45, 1359-1384.

Buck, N. (2000)Using panel surveys to study migration and residential mobility, In: Rose, D. (ed.) Researching social and economic change: the uses of household panel studies (Routledge: London), pp.250-272.

Cabinet Office (2011) Opening Doors, Breaking Barriers: A Strategy for Social Mobility, London.

Cheshire, P. (2011) Are mixed community policies evidence based? A review of the research on neighbourhood effects, in van Ham M., Manley D., Bailey N., Simpson L. \& Maclennan D. (eds) (2011) Neighbourhood Effects Research: New Perspectives. Springer: Dordrecht.

Clark, W.A.V. and Dieleman, F. (1996) Households and Housing: Choice and Outcomes in the Housing Market, Rutgers, The State University of New Jersey.

Clark, W. and Davies Withers, S. (1999) Changing jobs and changing houses: mobility outcomes of employment transitions.Journal of Regional Science 39: 653-673.

Clark, W.A.V. (2008) Re-examining the Moving to Opportunity Study and its contribution to changing the distribution of poverty and ethnic concentration.Demography, 45, 515535.

Clark, W.A.V. and Rivers, N. (2012) Community Choice in Large Cities: Selectivity and Ethnic Sorting Across Neighborhoods, in van Ham M., Manley D., Bailey N., Simpson L. \& Maclennan D. (eds) (2012) Understanding neighbourhood dynamics: new insights for neighbourhood effects research. Springer: Dordrecht.

Clark, W.A.V. and Morrison, P. (2011)Residential sorting, neighbourhood effects and social mobility: evidence from a large scale survey. In review.

Department for Business, Innovation and Skills (2009) Higher Ambitions. The future of universities in a knowledge economy, London.

Dietz, R. D. (2002)The estimation of neighbourhood effects in the social sciences: an interdisciplinary approach. Social Science Research 31, 539-575.

Dorling, D. (2010) Injustice: Why Social Inequality Persists. The Policy Press: Bristol.

Durlauf, S. N. (2004) Neighbourhood effects. Handbook of Regional and Urban Economics. J. V. Henderson and J. F. Thisse. Amsterdam, Elsevier. 4, 2174-2242.

Eliasson, K., Lindgren, U. and Westerlund, O. (2003)Geographical labor mobility, migration or commuting. Regional Studies 37, 827-837.

Feijten, P.M. and van Ham, M. (2009) Neighbourhood change... reason to leave? Urban Studies 46, 2103-2122.

Flatau, P. Hendershott P, Watson, R. Adn Wood G. (2004) What drives Australian housing careers? An examination of the role of labor market, social and economic determinants. Australian Housing and Urban Research Institute. Melbourne.

Friedman, S. (2011) Bringing Proximate Neighbours into the Study of US Residential Segregation, Urban Studies, 48, 611-639.

Friedrichs, J., G. Galster, et al. (2003) Neighbourhood effects on social opportunities: the European and American Research and policy context: editorial. Housing studies 18(6), 797-806. 
Goering, J. (2005) Expanding housing choice and integrating neighborhoods: The MTO experiment. In X. Briggs (ed.) The Geography of Opportunity: Race and Housing Choice in Metropolitan America. Washington D.C. The Brookings Institution , pp.128-149.

Goldthorpe, J and Llewellyn, C. (1987)Social Mobility and Class Structure in Modern Britain. Oxford, Oxford University Press.

Hedman, L., van Ham, M. and Manley, D. (2011) Neighbourhood choice and neighbourhood reproduction. Environment and Planning A 43, 1381-1399.

Hulchanski, J. D. (2007) The three cities within Toronto: income polarization among Toronto's neighbourhoods, 1970-2000. Centre for Urban and Community Studies. Research Bulletin Toronto, University of Toronto.

Johnson, M. Ladd, H., and Ludwig, J. (2002) The benefits and costs of residential mobility programmes for the poor. Housing Studies 17, 125-138.

LeClere, F. and McLaughlin, D. (1997) Family migration and changes in women’s earnings: a decomposition analysis. Population Research and Policy Review 16, 315-335.

Martin, J. and Lichter, D. (1983) Geographic mobility and satisfaction with life and work, Social Science Quarterly, 64, 524-535.

Meen, G. (2006) Modelling local spatial poverty traps in England. International Centre for Housing and Urban Economics Discussion Paper Reading, University of Reading.

Meen, G., Meen, J. and Nygaard, C. (2007) A tale of two Victorian cities in the 21st century. Discussion Paper No. 7, International Centre for Housing and Urban Economics, University of Reading.

Meen, G., Nygaard, C. and Meen, J. (2012) The Causes of Long-Term Neighbourhood Change, in van Ham M., Manley D., Bailey N., Simpson L. \& Maclennan D. (eds) (2012) Understanding neighbourhood dynamics: new insights for neighbourhood effects research. Springer: Dordrecht.

Mulder, C. 1993. Migration Dynamics: A life course approach. Amsterdam, PDOD Publishers.

Mulder, C., P. Hooimeijer (1999) Residential relocations in the life course. Population issues: An interdisciplinary focus. L. van Wissen and P. Dykstra (ed.) (Plenum Press New York), pp. 159-186.

Mulder, C, M Wagner (2010) Union dissolution and mobility: Who moves from the family home after separation? Journal of Marriage and Family72, 1263-1273.

Noble, M., Wright, G., Dibben, C., Smith, G., McLennan, D., Anttila, C., Barnes, H., Mokhtar, C., Noble, S.,Avenell, D., Gardner, J., Covizzi, I., Lloyd, M. (2004). The English Indices of Deprivation 2004 (ODPM: London).

Quillian, L. (2003)How long are exposures to poor neighbourhoods? The long-term dynamics of entry and exit from poor neighbourhoods.Population Research and Policy Review22(3), 221-249.

Quillin, L. (1999) Migration patterns and the growth of high poverty neighborhoods 19701990. American Journal of Sociology 105, 1-37.

Rabe, B. and Taylor, M. (2010) Residential mobility, quality of neighbourhood and life course events, Journal of the Royal Statistical Society: Series A 173: 531-555.

Robson, B., Lymperopoulou, K. and Rae, A. (2008) People on the move: exploring the functional roles of deprived neighbourhoods.Environment and Planning A, 40, 26932714.

Rosenbaum, J. (1995) Changing the geography of opportunity by expanding residential choice: lessons from the Gautreaux program. Housing Policy Debate 6, 231-269.

Rosenbaum, J. and Popkin, S. (1991) Employment and earnings of low income blacks who move to middle class suburbs. In The Urban Underclass, ed. C. Jencks and P. Peterson, pp. 342-56. Washington D.C. The Brookings Institution. 
Sampson, R. (2008)Moving to inequality: neighbourhood effects and experiments meet social social structure.American Journal of Sociology114: 189-231.

Schelling, T.C. (1971) Jounal of Mathematical Sociology Micromotives and Macrobehavior. New York, Norton.

Schill, M. H. and Wachter, S. M. (1995) Housing market constraints and spatial stratification by income and race. Housing Policy Debate 6, 1-28.

Scottish Executive (2004) Scottish Index of Multiple Deprivation 2004: Summary Technical Report (Scottish Executive: Edinburgh).

South, S. J., K. Crowder, et al. (2005)Exiting and entering high-poverty neighbourhoods: Latinos, Blacks and Anglos compared. Social Forces84(2): 873-900.

South, S. J. and K. D. Crowder (1997) Escaping distressed neighbourhoods: individual, community, and metropolitan influences. American Journal of Sociology102(4): 10401084.

Taylor, M. (ed), J. Brice, N. Buck, E. Prentice-Lane (2010) British Household Panel Survey User Manual Volume A: Introduction, Technical Report and Appendices (Colchester: University of Essex).

van Ham, M. and P. Feijten (2008) Who wants to leave the neighbourhood? The effects of being different from the neighbourhood population on wishes to move. Environment and Planning A 40(5): 1151-1170.

van Ham, M. and Clark, W.A.V. (2009)Neighborhood mobility in context: Household moves and changing neighbourhoods in the Netherlands. Environment and Planning A. 41, 1442-1459.

van Ham, M. and Manley, D. (2010) The effect of neighbourhood housing tenure mix on labour market outcomes: a longitudinal investigation of neighbourhood effects. Journal of Economic Geography 10, 257-282.

Varady, D. and Walker, C.(2003) Using housing vouchers to move to the suburbs: how do families fare? Housing Policy Debate 14, 347-382.

Welsh Government (2005). Welsh Index of Multiple Deprivation 2005: Technical Report.

Worner, S. M. (2006) The effects of assortative mating on income inequality: a decomposition analysis. Discussion Paper. Canberra, Centre for Economic Policy Research. 